\title{
A gestão por resultados na educação em quatro estados brasileiros
}

\author{
Catarina lanni Segatto
}

Fundação Getúlio Vargas (FGV)

Fernando Luiz Abrucio

Fundação Getúlio Vargas (FGV)

Este artigo discute as reformas recentes na política de educação em quatro estados brasileiros. A adoção das reformas resultou do baixo desempenho dos alunos nas avaliações, e sua disseminação foi influenciada por diversos atores e instituições, governamentais e não governamentais. Dessa forma, seus desenhos e processos de implementação foram diversos. O objetivo, portanto, deste artigo é compreender quais fatores influenciaram essas diferenças. Para isso, foi realizada uma análise comparada de quatro casos - Espírito Santo, Minas Gerais, Pernambuco e São Paulo - a partir de análise documental e de entrevistas. Verificou-se que alguns fatores foram responsáveis por essas diferenças, principalmente a trajetória das políticas educacionais, a realização de reformas anteriores e o modo como as reformas foram implementadas e negociadas com os atores envolvidos.

Palavras-chave: educação, política educacional, reforma administrativa, gestão por resultados

\section{La gestión por resultados en la educación en cuatro estados brasileños}

Este artículo analiza las recientes reformas en la política de educación de cuatro estados brasileños. La adopción de las reformas se debió a los malos resultados de los estudiantes en los exámenes y su propagación fue influenciada por los actores y instituciones, gubernamentales y no gubernamentales. Siendo así, sus diseños y procesos de implementación fueran distintos. El objetivo, por lo tanto, de este artículo es entender qué factores influyeron en estas diferencias. Para esto, se realizó un análisis comparativo de cuatro casos - Espírito Santo, Minas Gerais, Pernambuco y São Paulo - por medio de análisis documentales y de entrevistas. Se encontró que algunos factores fueron responsables de estas diferencias, principalmente la trayectoria de las políticas educacionales, la existencia de reformas en el pasado y cómo se implementaron las reformas y negociaron con los actores interesados.

Palabras clave: educación, política educacional, reforma administrativa, gestión por resultados

[Artigo recebido em 2 de fevereiro de 2015. Aprovado em 9 de dezembro de 2016.] 
The performance management in education in four Brazilian states

This paper discusses the recent reforms on educational policy in four Brazilian states. The adoption of these reforms was a result of students' poor performance in assessments and their dissemination was influenced by various actors and institutions, governmental and non-governmental. Thus, their designs and implementation processes were different. The objective of this paper is to comprehend the factors that have influenced these differences. Four cases were compared - Espírito Santo, Minas Gerais, Pernambuco and São Paulo - by documental and interviews analysis. It was found that some factors were responsible for these differences, mainly, the trajectory of educational policies, earlier reforms and how reforms were implemented and negotiated with stakeholders.

Keywords: education, educational policy, administrative reform, management by results 
Nos últimos vinte anos, a gestão por resultados foi adotada por governos em várias partes do mundo, sendo os casos mais conhecidos: Estados Unidos, Inglaterra e Nova Zelândia. Algumas características são comuns a essas experiências, em primeiro lugar, a adoção de metas e indicadores serviu para nortear as políticas públicas. Além disso, elas foram combinadas a mecanismos de contratualização, a partir dos quais os atores envolvidos seriam cobrados, premiados, punidos. Os mecanismos de aferição de desempenho também foram utilizados como instrumento de publicização, bem como de accountability, entendida como responsabilização, sobre a gestão (CENTRO LATINOAMERICANO DE ADMINISTRAÇÃo PARA o DESENVOLVIMENTO, 2000).

A gestão por resultados também chegou às políticas educacionais a partir do uso de indicadores de desempenho e da avaliação dos sistemas de ensino, das escolas e dos professores. As mudanças iniciais buscavam um diagnóstico da política e de seus resultados, mas depois elas incluíram mecanismos de incentivo. A gestão por resultados também foi importante para o fortalecimento do controle democrático, pois permitiu que a comunidade escolar e/ou outros agentes sociais pudessem exercer a accountability sobre a administração pública (WANG; BECKETT; BROWN, 2006).

No Brasil, mais intensamente a partir da década de 1990, os instrumentos de gestão por resultados têm sido adotados na administração pública. As avaliações foram os primeiros instrumentos a serem disseminados na educação. $E$, assim como na experiência internacional, foram adotados mecanismos de incentivo, premiação e sanção.

Apesar da disseminação desses instrumentos, a literatura é pouco consensual sobre os seus resultados. Uma parte dela concebe esse processo como negativo em si, mostrando como esse modelo não seria capaz de mudar os problemas educacionais mais profundos (FREITAS, 2004). Outra parcela de estudiosos afirma que tais políticas seriam, em si, sempre positivas (GALL; GUEDES, 2009). Há ainda uma grande quantidade de estudos que, sem alcançar consenso, discutem os efeitos positivos e negativos dos incentivos aos professores (PODGURSKY; SPRINGER, 2007).

No entanto, pouco se avançou na compreensão sobre os fatores que influenciaram a adoção dessas reformas no Brasil. O objetivo do presente artigo é analisar concretamente como se deu a reforma educacional orientada por resultados em quatro governos estaduais brasileiros, particularmente no período de 2007-2010. Os casos selecionados foram os de Espírito Santo, Minas Gerais, Pernambuco e São Paulo. Em todos eles se buscou estudar o processo reformista e os instrumentos 
adotados. De antemão, ressalta-se que a pesquisa revelou que há mais de uma forma de construção e de funcionamento da gestão por desempenho na educação.

Para isso, este artigo discute, inicialmente, o sentido das reformas da gestão por resultados, com enfoque no caso da educação. São realçados os avanços encontrados na experiência internacional, mas igualmente são destacados os limites e as nuances desse processo, que é menos uniforme do que afirma tanto a literatura detratora do modelo, como a enaltecedora dele. Em seguida, é apresentada uma pequena introdução sobre as origens de um paradigma de gestão por desempenho na educação brasileira. Por fim, os modelos de gestão por resultados adotados pelos estados são comparados a partir da descrição e análise dos quatro casos escolhidos, realçando suas similaridades e diferenças.

\section{A gestão por resultados na educação: potencialidades e problemas}

A introdução de mecanismos de gestão por resultados teve seu primeiro impulso na Grã-Bretanha em meados da década de 1980 (ABRUcıO, 2006). Esse processo se disseminou para outros países anglo-saxões, como a Austrália e a Nova Zelândia (GRUENING, 2001), e para os países nórdicos. Os governos estaduais norteamericanos tornaram-se um grande laboratório de inovações, principalmente a partir da década de 1990 (OSBORNE; GAEBLER, 1995). Nesse momento, a gestão por resultados também alcançou alguns países da América Latina, como Argentina, Chile, El Salvador, México, Nicarágua e Brasil (Programa de Promoción DE LA REForma Educativa de AMÉRICA LATINA y El CARIBE, 2003).

No seu modelo inicial, a gestão por resultados procurava, basicamente, adaptar técnicas da administração privada para a administração pública (GRAY; JENKINS, 1995). Isso se mostrou equivocado. E vários autores realçaram a necessidade de se utilizar metas, indicadores e formas de contratualização que seguissem os valores básicos do setor público em uma democracia, o que significou busca da efetividade e da equidade, participação política e accountability, bem como a profissionalização contínua de servidores movidos por um ethos público orientado pela probidade e pelo compromisso de servir bem aos cidadãos (CENTRO LATINOAMERICANO DE AdMINISTRAÇÃo PARA O DESENVOLVIMENTO, 2000).

De qualquer modo, é possível verificar que esse modelo administrativo foi implementado por meio de combinações e estratégias diferentes para lidar com a melhoria do desempenho governamental (POLITT; BOUCKAERT, 2000). Em alguns países, a preocupação maior foi com a publicização de metas e indicadores, que mobilizariam a sociedade em prol da melhoria dos resultados; noutras experiências, foram os incentivos criados, seja para os próprios servidores públicos, seja por meio 
da competição administrada entre órgãos públicos e entidades não governamentais (Centro latinoamericano de Administração para o Desenvolvimento, 2000). Ressalte-se que, sobretudo nos últimos quinze anos, cresceu o número de governos que têm feito reformas em prol da maior accountability dos resultados alcançados, além de ter aumentado a importância da participação social e de uma governança mais inclusiva e negociadora com os diversos atores sociais em uma lógica de gestão em rede (PETERS, 2008).

O interessante é notar que o controle social, por meio da adoção dos instrumentos adequados de gestão por resultados, pode ser potencializado, como afirmam Abrucio e Loureiro (2004):

(...) a utilização de controles dos resultados da administração pública é uma das maiores novidades em termos de accountability democrática. Tratase de responsabilizar o poder público pelo desempenho dos programas governamentais. Isso pode ser feito por órgãos do próprio governo contanto que tenham autonomia para fazê-lo -, por agências independentes organizadas e financiadas pela sociedade civil e, ainda, pelas instituições que tradicionalmente têm realizado o controle administrativo-financeiro. $\mathrm{O}$ novo aqui nem tanto são os atores que fiscalizam, e sim o que se procura fiscalizar. Nessa nova modalidade, os governantes eleitos e os burocratas serão avaliados substantivamente pelo cumprimento das metas propostas. Além das possíveis penalidades que os cidadãos possam vir a impor aos ocupantes de cargos públicos, o mais importante é que esse instrumento de accountability democrática orienta-se por diretrizes mais claras que melhoram o debate e, desse modo, servem não só como forma de controle, mas igualmente como aprendizado cívico (ABRUCIO; LOUREIRO, 2004, p. 84-85).

A gestão por resultados alcançou também a área educacional, e sua implementação, tal como nas reformas mais gerais, não se deu da mesma maneira em todos os lugares. No caso dos Estados Unidos, houve tanto a introdução de incentivos por meio da remuneração por desempenho para diretores e professores, por exemplo, a criação de Charter Schools, em que foram combinadas maior autonomia e flexibilidade das escolas com contratualização de resultados (WANG; BeCKetT; BRoWn, 2006; GALL; GUedes, 2009). Alguns países, como o Brasil, seguiram a lógica norte-americana com a adoção de mecanismos de incentivo e contratualização, e, em outros países, como o Canadá, as mudanças incluíram somente o fortalecimento das avaliações.

Em todos os casos, sejam governos nacionais ou subnacionais, as mudanças incluíram a adoção e o fortalecimento das avaliações e do uso de indicadores para, 
de um lado, aferir o desempenho educacional e, de outro, aumentar a publicização e, geralmente, fortalecer o controle social.

Ribeiro (2010) mostra que essa onda reformista também se espalhou pela América Latina. A autora analisa a atuação dos movimentos sociais na melhoria da qualidade da educação em cinco países, Argentina, Brasil, Chile, Colômbia e México. Os movimentos nesses países - Proyecto EducAR, Todos Pela Educação, Fundación Educación, Fundación Empresarios por la Educación e Mexicanos Primero-, a partir da sua atuação advocatória, influenciaram tanto a adoção e o fortalecimento desses instrumentos, como o seu uso pela sociedade em geral.

Além dessas organizações, outros fatores também foram fundamentais para a disseminação dos instrumentos de gestão por resultados na educação. No caso brasileiro, alguns organismos internacionais e agências de fomento, como o Banco Mundial, a United Nations Educational, Scientific, and Cultural Organization (Unesco) e o Programa de Promoción de la Reforma Educativa de América Latina y el Caribe (Preal), influenciaram esse processo a partir da vinculação do uso de avaliações e metas para o recebimento de financiamento (FARIA; FILGUEIRAS, 2007; Segatto; Abrucio, 2011).

A atuação de determinados dirigentes públicos e o apoio da burocracia pública também foram importantes nesse processo. Os primeiros influenciaram a entrada desse assunto na agenda governamental. E os segundos conferiram aceitação e legitimidade a esses instrumentos. A literatura chama atenção para uma prática recorrente, o gaming, que, na educação, pode resultar, por exemplo, no controle intencional do desempenho pelos professores ou gestores escolares para que as metas futuras não sejam aumentadas; na exclusão da avaliação de alunos que não alcançam o nível adequado; e na ênfase excessiva aos conteúdos e disciplinas que são avaliados. ${ }^{1}$

O resultado desse processo reformista foi a mudança na orientação das ações em duas dimensões. Em uma dimensão estratégica, as avaliações, metas e indicadores passaram a orientar o planejamento dos ministérios de educação e, nesse caso, das secretarias estaduais de educação. $\mathrm{E}$, em uma dimensão operacional, mudaram o sentido de implementação da política, já que as ações de todos os stakeholders, inclusive das escolas, passaram a ter como foco a aprendizagem do aluno.

O que se observa na literatura sobre as reformas é que, apesar de se basearem em ideias comuns, de controle por resultados, cada desenho de reforma produz um tipo de resultado nas políticas públicas. O controle por resultados não é, portanto,

\footnotetext{
${ }^{1}$ De acordo com Hood (2007), gaming refere-se a uma mudança deliberada ou fraude de números com a intenção de melhorar a posição de um indivíduo ou organização (HOOD, 2007).
} 
um instrumento imutável. Ao contrário, ele foi resultado da construção negociada e incremental entre os atores sociais, políticos e a burocracia. Em função disso, apresentou diferentes desenhos nos países que o adotaram. Como apresentado, alguns países avançaram na construção de sistemas de avaliações e outros, na criação de metas, indicadores, mecanismos de contratualização e de remuneração por desempenho. Foi também diferente o seu papel no aumento da transparência e na publicização dos resultados educacionais, no fortalecimento de espaços de diálogo e negociação e no empoderamento da sociedade civil.

\section{A gestão por resultados no Brasil}

No Brasil, a gestão por resultados foi adotada de maneira mais intensa a partir de 1995, com a criação do Ministério da Administração Federal e Reforma do Estado (Mare). A reforma pretendia avançar em relação à administração burocrática criada com o Departamento Administrativo do Serviço Público (Dasp) com a introdução do modelo gerencialista, que tem como um de seus pilares a gestão por resultados.

Esse processo levou à descentralização/desconcentração de determinadas funções, que foram também atribuídas a organizações da sociedade civil e empresas privadas; à criação de organizações sociais e de mecanismos de contratualização de resultados; e a uma maior avaliação das políticas públicas (ABRUCıO, 2010).

Além disso, a reforma no plano federal influenciou a adoção de determinados instrumentos de gestão por resultados pelos governos estaduais (ABRUCIO; GAETANI, 2006, p. 21). E outros fatores influenciaram as mudanças nos estados. Destaca-se a crise fiscal em que os estados estavam inseridos e a atuação do Conselho Nacional de Secretários de Estado e Administração (Consad) e dos empreendedores vindos da experiência de reforma federal (ABRUCIO, 2010; Abrucio; GAETANI, 2006; GAETANI, 2010).

As reformas pioneiras, como a de Minas Gerais, influenciaram a adoção da gestão por resultados por outros estados. O que se deu, principalmente, por meio do Consad e do Programa Nacional de Apoio à Modernização da Gestão e do Planejamento dos Estados Brasileiros e do Distrito Federal (PNAGE).

É importante apontar que, antes disso, pouca alteração havia sido promovida nas administrações estaduais, uma vez que os estados não foram modernizados nas reformas anteriores, que ficaram restritas ao Governo Federal. Somente com a Constituição Federal de 1988, algumas mudanças foram introduzidas, como a democratização, a descentralização e a profissionalização da burocracia (ABRUcıo; PEDROTI; Pó, 2009). Na educação, em alguns estados, houve reformas e inovações, 
mas, na grande parte dos estados, foi a Constituição que promoveu importantes mudanças, como a sua universalização e descentralização (SEGATTo, 2011).

\section{A disseminação da gestão por resultados na política educacional brasileira}

No caso das políticas estaduais de educação, a disseminação da gestão por resultados foi influenciada, principalmente, pelas relações intergovernamentais, especificamente pelos mecanismos de indução do Governo Federal a estados e municípios, que se fortaleceram no Governo Fernando Henrique Cardoso - Sistema Nacional de Avaliação da Educação Básica (Saeb), Censo Educacional e reforma curricular, por exemplo-e no Governo Lula - Prova Brasil, Índice de Desenvolvimento da Educação Básica (Ideb) e Plano de Ações Articuladas (PAR) (SEGATTo, 2011).

Outros atores nacionais foram importantes para isso, especialmente o Movimento Todos Pela Educação e o Conselho dos Secretários Estaduais de Educação (Consed). Na primeira década dos anos 2000, o Todos Pela Educação estabeleceu cinco metas para a educação brasileira e, a partir disso, as dissemina e acompanha o seu alcance. O Consed promoveu discussões sobre avaliações, metas e sistemas de remuneração por desempenho em suas reuniões, possibilitando, assim, um intercâmbio das experiências e a sua disseminação (SEGATTO, 2011).

Exemplo disso é que, na análise de um questionário respondido por nove secretarias, Ribeiro (2010) mostra que todas as secretarias estaduais de educação respondentes conhecem o Ideb, o Ideb para sua unidade da Federação, as cinco metas do Todos Pela Educação e possuem metas próprias. Além disso, a maior parte delas utiliza as metas do Ideb, do Todos Pela Educação e suas metas próprias na formulação de política. ${ }^{2}$

Apesar da semelhança entre esses estados, há diferentes usos e entendimentos sobre as metas e indicadores educacionais. Nas respostas abertas, algumas secretarias apontam que esses instrumentos mudaram a própria formulação da política, estando ligados ao planejamento e à capacitação; outras, que eles mudaram a lógica nas escolas, o foco passou a ser o aluno e os professores passaram a se esforçar mais (RIBEIRO, 2010).

Outras diferenças se referem à premiação, pactuação e divulgação. Somente em alguns estados havia premiação dos servidores públicos segundo os resultados alcançados, sendo que no Acre, Minas Gerais e Pernambuco havia a pactuação das metas com as escolas. Há ainda uma grande variação no modo como as metas são divulgadas e discutidas com as escolas, pais e sociedade civil. Há casos em que elas

\footnotetext{
${ }^{2}$ As seguintes secretarias responderam ao questionário: Acre, Ceará, Distrito Federal, Maranhão, Minas Gerais, Paraíba, Pernambuco, Rio de Janeiro e Rio Grande do Sul.
} 
são discutidas na escola, como em Minas Gerais, e outros em que são distribuídos boletins, como no Rio Grande do Sul. De maneira geral, foram apresentadas poucas ações concretas de divulgação e debate dos resultados.

\section{A experiência dos estados brasileiros: os casos de Espírito Santo, Minas Gerais, Pernambuco e São Paulo}

Há, como apresentado, um debate mais geral sobre o controle por resultados nas reformas administrativas. No entanto, há pouca discussão tanto sobre a sua disseminação e adoção na educação quanto sobre o conteúdo das reformas e o modo como elas foram implementadas (SEGATTO, 2011). A partir disso, neste artigo, foi realizado um estudo comparativo que permite a busca por semelhanças e diferenças entre os casos e, assim, o aprofundamento do debate.

\section{Método de pesquisa}

A pesquisa empírica foi realizada por meio da análise qualitativa comparada de quatro casos - Espírito Santo, Minas Gerais, Pernambuco e São Paulo -, que foram escolhidos, pois propuseram ideias reformistas, realizaram as reformas educacionais e tiveram caráter de liderança nesse processo. No entanto, eles são diferentes em três sentidos: no seu histórico institucional, na forma como implementaram as reformas no período recente e em seus contextos econômicos, políticos e sociais.

Os dados da análise comparada foram coletados por meio de pesquisas anteriormente realizadas, de documentos sobre as reformas educacionais, da IV Reunião Ordinária do Consed de 2010 e de cerca de 10 entrevistas semiestruturadas realizadas em 2010. As entrevistas foram realizadas com as secretarias estaduais de educação dos quatro estados, com outros atores ligados ao setor, como sindicatos e com especialistas da política educacional. Os dados coletados foram analisados de forma qualitativa.

\section{Espírito Santo}

Em 2003, a política educacional no Espírito Santo encontrava-se em uma condição precária. Havia dívidas com fornecedores e prestadores de serviços, atraso nos salários do magistério e no calendário escolar e obras paralisadas. Com a posse de Paulo Hartung (PMDB) na Secretaria Estadual de Educação em 2003, foi iniciada a recuperação do equilíbrio financeiro da secretaria, com pagamento de fornecedores, dos convênios e dos profissionais (ESPÍRITO SANTO, 2010). Além disso, houve a alteração do processo de seleção e treinamento dos profissionais 
da educação (com ênfase nos diretores), adoção do planejamento estratégico e da remuneração por desempenho.

A reforma se baseou no Plano de Desenvolvimento do Espírito Santo 2025 e no Compromisso Todos Pela Educação; assim como o Plano Estratégico da Secretaria, intitulado Nova Escola, que foi composto por metas retiradas dos documentos supracitados.

Os entrevistados apontaram que, além da influência desse processo de reforma mais geral, as reformas realizadas no Ceará, Minas Gerais, Pernambuco e São Paulo, as experiências internacionais e a atuação do Movimento Todos Pela Educação foram fundamentais para a mudança. Mas, mais do que os fatores citados, os entrevistados acreditam que sem a liderança do Governador do Estado e do Secretário de Educação, a reforma não teria sido implementada.

Em 2003, houve a criação da Assessoria de Planejamento e Gestão Estratégica, o fortalecimento e a expansão do Programa de Avaliação da Educação Básica do Espírito Santo (Paebes), criado em 2000. ${ }^{3}$

De 78 municípios, 75 redes municipais de ensino e 26 escolas privadas aderiram ao sistema, que permitia que as escolas tivessem resultados anuais mais rapidamente do que as avaliações nacionais. E os alunos em fase de alfabetização eram avaliados duas vezes ao ano, no começo e no final do ano letivo, com a finalidade de subsidiar a atuação dos professores ao longo do ano.

Além dessas ações, a secretaria elaborou um modelo de remuneração por desempenho. Esse processo durou dois anos, já que foi negociado com o sindicato. Vale ressaltar, nesse ponto, que a Assembleia Legislativa não foi citada como um ator de embate na aprovação na reforma, ainda que ela ainda não tivesse sido aprovada no momento da pesquisa.

O modelo de remuneração por desempenho necessitava solucionar importantes problemas da rede estadual do Espírito Santo: o alto índice de absenteísmo dos professores; problemas do Ideb, pois o indicador não considerava os alunos que não faziam a prova; e a falta de um currículo unificado. A proposta de remuneração por desempenho é descrita no Quadro 1.

\footnotetext{
${ }^{3}$ Em 2000, o Paebes avaliou a 2o série do Ensino Fundamental; em 2004, passou a avaliar a 4a e 8a séries do Ensino Fundamental e 1a série do Ensino Médio nas disciplinas de Língua Portuguesa, Matemática, Física, Química e Biologia. Em 2008, houve a Avaliação Diagnóstica da Alfabetização em turmas de 1으 eo séries/anos do Ensino Fundamental e a avaliação da 1a série do Ensino Médio nas disciplinas de Língua Portuguesa e Matemática. Antes de 2004 , as provas eram feitas pela própria secretária. Devido à expansão da avaliação, a Secretaria contrata empresas para implementar as provas.
} 
Quadro 1 - Modelo de remuneração por desempenho do Espírito Santo

\begin{tabular}{|c|c|}
\hline Critérios & Detalhamento \\
\hline \multirow{4}{*}{$\begin{array}{l}\text { Equipe } \\
\text { Aprendizagem + } \\
\text { Esforço }\end{array}$} & Aprendizado dos alunos: avaliação de sistema (IRE) \\
\hline & $\begin{array}{l}\text { 1) \% de alunos nos níveis de desempenho insuficiente (2), } \\
\text { básico (6), adequado (8) e avançado (10). } \\
\text { 2) Alunos ausentes da avaliação do sistema (0). }\end{array}$ \\
\hline & Esforço: níveis socioeconômico e de ensino (IEE) \\
\hline & $\begin{array}{l}\text { 1) Nível socioeconômico } \\
\text { Renda familiar, escolaridade da mãe e ocupação do } \\
\text { responsável pelo domicílio. } \\
\text { 2) Nível de ensino } \\
\text { Esforço é considerado maior para o Ensino Médio. }\end{array}$ \\
\hline \multicolumn{2}{|r|}{ Classificação em 11 faixas de merecimento (50 a 100\%) (IMU) } \\
\hline \multirow[b]{2}{*}{ Individual } & Contribuição para o resultado = Presença \\
\hline & $\begin{array}{l}\text { 1) Contribuição ao desempenho (critério de "corte") (ICD) } \\
2 / 3 \text { do período de avaliação na mesma unidade (122 dias - } \\
\text { entre } 01 / 05 \text { e } 31 / 10 \text { ). } \\
\text { 2) Valorização da assiduidade (redutor por ausência, exceto } \\
\text { férias) (FVA) } \\
7 \% \text { de desconto do valor do bônus para cada dia de registro } \\
\text { de ausência. } \\
\text { Obs.: acima de } 9 \text { ausências, profissionais ainda recebem o piso ( } 30 \% \\
\text { do valor a que teriam direito). }\end{array}$ \\
\hline
\end{tabular}

Fonte: Secretaria da Educação do Estado do Espírito Santo (2010).

Como mostra o Quadro 1, o desempenho dos alunos era divido por faixas de competências e segundo seu nível socioeconômico e não por média da escola. Para os entrevistados, isso permitia que não fossem comparados municípios ou escolas muito distintos. As características do sistema levavam em consideração os problemas do controle por resultados citados pela literatura, como o gaming. Essas características foram pensadas justamente pela ocorrência de tais problemas em sistemas existentes em outros estados.

Outras mudanças foram promovidas, como a ampliação do salário de ingresso na carreira; mudança na seleção dos professores por meio de prova objetiva e discursiva, avaliação de titulação, curso de formação e avaliação de competência didática; formação continuada aos servidores; e um novo processo seletivo para diretores. A reforma na rede estadual de ensino do Espírito Santo se baseou não só no foco no desempenho por meio do fortalecimento dos sistemas de avaliação e da introdução da remuneração por desempenho, mas também nos meios para 
o alcance de um melhor desempenho, como a profissionalização da burocracia. Consistiu, portanto, numa experiência de reforma que optou pela combinação de instrumentos, colocados como antagônicos em outras experiências.

\section{Minas Gerais}

A reforma na política educacional em Minas Gerais ocorreu em 2006, no governo de Aécio Neves. O Choque de Gestão e, posteriormente, o Acordo de Resultados foram implementados a partir de 2003 em todas as secretarias do governo estadual. Em um primeiro momento, a reforma visava ao ajuste fiscal no estado e, em um segundo momento, à melhoria do desempenho por meio da pactuação de metas entre os órgãos do governo com os superiores hierárquicos.

Na política educacional, o formato da reforma era o seguinte:

[...] na 1a geração do Acordo foi pactuado o cumprimento de metas entre o Governador e o Secretário de Educação. As metas foram definidas em âmbito macro, caracterizando outcomes, e representavam compromisso de todos na Secretaria de Educação. Já a 2a geração do Acordo de Resultados revela um novo desdobramento da pactuação de metas: entre o Secretário de Educação e os responsáveis pelas regionais, chegando até o nível das escolas (Formoso, 2009, p. 73).

Na educação, já havia um terreno propício para a implementação da reforma em função da preexistência do sistema de avaliação, que foi usado para o controle dos resultados educacionais das escolas. Nesse sentido, o sistema de avaliação no estado não precisou ser criado ou fortalecido, como nos casos mais recentes, pois ele já estava consolidado.

Minas é um dos poucos estados a manter um sistema próprio de avaliação educacional e foi o primeiro a realizar avaliação externa das suas escolas. Em 1992, antes mesmo que o MEC implantasse o seu sistema de avaliação, já estavam sendo realizados os primeiros testes por meio do Programa de Avaliação da Escola Pública de Minas Gerais. Desde então, sucessivas mudanças metodológicas e estruturais foram introduzidas (PINTO; SARAIVA, 2010, p. 123).

Segundo os entrevistados, a secretaria ampliou o alcance da avaliação a partir da criação de uma avaliação da alfabetização e de um banco de itens para os professores aplicarem as provas em suas escolas. A secretaria controlava a utilização do banco de itens, o que permitia verificar as deficiências dos próprios professores e, assim, elaborar a sua capacitação. 
No âmbito da contratualização, a secretaria fazia os contratos com suas superintendências e escolas. Estudava a situação das cerca de quatro mil escolas e sugeria uma proposta online. Em seguida, o diretor da escola discutia a proposta com seus professores, com a comunidade e com o colegiado da escola, propunha as mudanças, e a secretaria examinava e negociava com as escolas o que era razoável para elas. Por fim, era feita a pactuação ou a contratualização de metas.

Para isso, conforme relatado, outras duas mudanças foram necessárias: a elaboração de um currículo base comum e de metas. A meta de cada escola era projetada a partir dos indicadores finalísticos da escola, que eram baseados em um valor referência (valor apurado do indicador do ano anterior). Esses indicadores levavam em conta o resultado dos alunos nas provas de Língua Portuguesa e Matemática, a distorção idade-série (o fluxo escolar) e o percentual de conclusão dos alunos nos Ensino Médio e Fundamental. A partir do valor observado, mediase o alcance ou não da meta e, consequentemente, o valor do prêmio. Para o cálculo do valor do prêmio, também eram considerados os dias de efetivo exercício do servidor público, a nota da coordenadoria regional e a nota da Secretaria de Educação na primeira fase do acordo.

Além disso, assim como no caso do Espírito Santo, houve uma maior profissionalização da burocracia a partir de mudanças no plano de carreira, uma nova tabela de vencimentos e a introdução da certificação dos diretores.

O que se observa é que, diferentemente dos outros estados, em Minas Gerais já havia uma trajetória anterior de reformas. Houve um processo pioneiro de municipalização e, em 1994, a introdução das eleições para diretor e a criação do sistema de avaliação. O que foi anterior à adoção pelo próprio Governo Federal das avaliações nacionais. Essa trajetória de mudanças na educação diminui o embate entre o governo estadual, o sindicato e a Assembleia Legislativa no Estado.

\section{Pernambuco}

No caso de Pernambuco, a reforma foi idealizada pelo Governo de Jarbas Vasconcelos (PMDB) (2003 a 2006), enquanto Mozart Neves Ramos foi secretário estadual de educação. No entanto, ela foi implementada efetivamente no governo seguinte de Eduardo Campos (PSB), que governou de 2007 a $2010^{4}$ e foi reeleito em 2011. De forma semelhante ao caso do Espírito Santo, o próprio sistema de avaliação foi criado há cerca de dez anos e foi fortalecido mais recentemente. Em seguida, outras mudanças puderam ser implementadas, como a contratualização e a bonificação.

\footnotetext{
${ }^{4}$ Nesse governo, a reforma denominou-se Programa de Modernização da Gestão Pública e foi implementada nas áreas da educação, finanças, segurança e saúde.
} 
O Sistema de Avaliação da Educação de Pernambuco (Saepe) foi introduzido em 2000. A primeira etapa foi realizada em 2000 e 2002, e a avaliação foi aplicada novamente em 2005. Em 2008, o Saepe deixou de ser bianual e passou a ser anual, avaliando todos os alunos da zona rural e urbana e das escolas municipais e estaduais que têm a partir de cinco alunos por sala de aula da 2aa $4^{2} \underline{a}$ e $8^{a} \underline{a}$ séries do Ensino Fundamental e do 3o ano do Ensino Médio.

Com o Ideb, o governo elaborou o Índice de Desenvolvimento da Educação de Pernambuco (Idepe). O cálculo do Idepe considera dois critérios complementares: o fluxo escolar e o desempenho dos alunos da 4a e 8a séries do Ensino Fundamental (anos iniciais e finais) e do 3o ano do Ensino Médio nos exames do Saepe em Língua Portuguesa e Matemática. Com esse indicador, foram modificados os critérios para a bonificação, baseando-se na média de proficiência dos estudantes no Saepe e na média da taxa de aprovação dos estudantes (medida pelo censo escolar). ${ }^{5}$

A existência do sistema de avaliação possibilitou a introdução de um processo de seleção para diretores e da contratualização. Após a eleição do diretor, ele assinava com a Secretaria de Educação um termo de gestão ou contrato de gestão de metas de resultados. Em contrapartida, a secretaria enviava os recursos à escola para que os resultados fossem alcançados. Vale ressaltar que, segundo Mozart Neves Ramos, era necessária a profissionalização da direção, que antes era um cargo de confiança, para a introdução da contratualização.

Como apresentado, as metas eram firmadas por meio de um termo de compromisso entre a escola e a secretaria. Cada escola tinha uma meta específica e todas as escolas tinham uma meta única para alcançarem em 2021. Além disso, no termo de compromisso, a secretaria se responsabilizava por ajudar a escola na elaboração e implementação de sua proposta pedagógica, oferecendo infraestrutura necessária e desenvolvendo ações que garantissem a presença de professores em todas as suas turmas e disciplinas; e a escola se responsabilizava por implantar a matriz curricular, desenvolver o currículo integralmente, cumprir o calendário escolar, garantir o acesso e a permanência do aluno na escola, apoiar todas as ações que visassem ao sucesso escolar e preencher os dados solicitados pelo censo escolar.

Se alcançada $50 \%$ da meta firmada no termo de compromisso, o bônus de desempenho educacional era concedido aos servidores das escolas. O valor da bonificação variava de acordo com o percentual da meta atingido pela escola, de acordo com o salário-base do servidor, mas era necessário que ele tivesse um exercício mínimo de seis meses na escola.

\footnotetext{
${ }^{5}$ No caso do Idepe, o fluxo escolar considera "taxa de aprovação em cada uma das séries da educação básica oferecidas pela escola, conforme os procedimentos do Censo Escolar, que apura os índices anuais de aprovação, reprovação e abandono" (SISTEMA DE INFORMAÇÕES DA EDUCAÇÃo DE PERNAMBUCO, 2016).
} 
Observa-se que o caso de Pernambuco é semelhante ao do Espírito Santo, na medida em que as mudanças foram realizadas mais recentemente e implementadas em fases. Isto é, foi necessário, em primeiro lugar, o fortalecimento do sistema de avaliação e da profissionalização da burocracia para, em seguida, realizar-se a contratualização de resultados entre secretaria e escolas.

\section{São Paulo}

Assim como em Minas Gerais, o sistema de avaliação (Sistema de Avaliação de Rendimento Escolar do Estado de São Paulo - Saresp) já estava consolidado no Estado de São Paulo - ele foi criado em 1996. Isso permitiu que, nas mudanças mais recentes, fosse criado o Índice de Desenvolvimento da Educação do Estado de São Paulo (Idesp) e introduzida a remuneração por desempenho. Essas mudanças ocorreram na gestão de Maria Helena Guimarães de Castro, que assumiu o cargo em julho de 2007, no Governo de José Serra (PSDB) 6 .

Com a criação do Idesp, o desempenho dos alunos passou a ser controlado e foram estipuladas metas anuais para cada escola a fim de que as mesmas atingissem a meta de longo prazo (em 2030). O Idesp era composto pelo desempenho dos alunos e pelo índice de fluxo escolar. Com o índice e o absenteísmo do professor, era calculada a bonificação. O bônus era concedido ao trabalho coletivo, ou seja, à escola, incluindo professores, funcionários, coordenadores e diretor. Assim como no caso do Espírito Santo, o alto nível de absenteísmo dos professores e o elevado número de professores temporários eram grandes problemas da rede estadual.

Para que a avaliação pudesse ser utilizada para o cálculo do índice e da bonificação, foram implementados um currículo mínimo obrigatório e o uso dos materiais didáticos e do Caderno do Professor. Além disso, na gestão de Paulo Renato Souza, foi introduzida a prova para progressão na carreira dos professores e para o ingresso dos professores substitutos na rede estadual.

Outro projeto implementado ainda na gestão de Maria Helena Guimarães de Castro (2007 a 2009) e continuado por Paulo Renato Souza (Secretário da Educação do Estado de São Paulo de 2009 a 2010) foi uma parceria entre secretaria, Instituto Fernand Braudel de Economia Mundial e Instituto Itaú Social. Inspirada na reforma realizada em Nova York, a iniciativa consistia em um projeto-piloto em dez escolas localizadas na região leste de São Paulo7.

\footnotetext{
${ }^{6}$ Já haviam sido concedidas bonificações em governos anteriores, no entanto não estavam atreladas ao desempenho dos alunos da rede estadual de ensino.

${ }^{7} \mathrm{O}$ projeto introduziu nas escolas professores coordenadores e coordenadores de pais. Os primeiros auxiliam a melhoria dos professores a partir do acompanhamento das aulas, do planejamento das atividades e das reuniões pedagógicas. Os segundos realizam o elo entre a direção da escola e as famílias dos alunos (ALVAREZ, 2010).
} 
Apesar da criação da prova para a progressão da carreira e para a seleção dos professores substitutos, pouco foi feito para profissionalizar a burocracia, como nos casos anteriores. Não houve modificação na carreira dos diretores escolares e nas diretorias regionais de ensino. Apesar disso, os diretores, ao contrário dos outros estados, são selecionados por meio de concurso público.

Mais recentemente, entre 2011 e 2012, mudanças foram feitas para criar capacidade institucional, especialmente nas diretorias regionais de ensino e na secretaria. Na secretaria, as coordenadorias regionais foram transformadas em coordenadorias temáticas - Educação Básica, monitoramento e avaliação, estrutura e serviços escolares e recursos humanos - a fim de reduzir a replicação de tarefas. $\mathrm{E}$ as diretorias regionais de ensino estão sendo fortalecidas e profissionalizadas, para que realizem as atividades de gestão administrativa e financeira, que hoje sobrecarregam os diretores.

Além disso, alguns dos entrevistados apontaram que essas mudanças foram pouco discutidas com os sindicatos, escolas e Conselho Estadual de Educação, o que gerou resistência dos professores e dos sindicatos durante esse processo. Esse é o caso em que a reforma foi menos incremental e negociada ao longo do processo. Em função disso, sua implementação enfrentou entraves e rupturas, como a saída da secretária do cargo.

\section{Ideias semelhantes e reformas diferentes?}

As mudanças, nos quatro estados, incluíram a adoção e/ou o fortalecimento de avaliações, metas, indicadores, premiações e de mecanismos de contratualização de resultados. Enquanto os primeiros estiveram presentes nos quatro estados, o último foi apenas implementado em dois deles. O conjunto desses instrumentos, portanto, constitui o que significou a gestão por resultados nas políticas estaduais de educação. No entanto, ainda que tenha havido semelhanças, assim como ocorreu na experiência internacional, houve uma variação do que constituiu a gestão por resultados entre os estados.

A disseminação da gestão por resultados nesses estados foi influenciada pelo fortalecimento desses instrumentos no Governo FHC e Lula e pelos mecanismos de indução do Governo Federal. Houve também a influência de organismos internacionais, como a Unesco, o Preal e o Banco Mundial, do Todos Pela Educação e do Consed. Apesar disso, segundo os entrevistados, as escolhas dos atores locais foram fundamentais para a introdução das reformas nas agendas governamentais. E, nos casos de Espírito Santo e Pernambuco, os estados pioneiros serviram de inspiração não só para a adoção dos instrumentos, mas também para a sua melhoria, o que funcionou como um mecanismo de aprendizagem. 
Em relação aos processos de implementação dos instrumentos de gestão por resultados, é importante notar que as mudanças encontraram mais facilidade nos estados em que houve reformas anteriores, ou seja, naqueles em que havia um sistema de avaliação consolidado - Minas Gerais e São Paulo. No outros dois casos, Espírito Santo e Pernambuco, os sistemas precisaram ser fortalecidos para a implementação de índices, metas e da remuneração por desempenho. Isso foi especialmente reforçado por Mozart Neves Ramos, que, além de enfatizar a importância do sistema de avaliação, enfatizou a necessidade de profissionalização da burocracia.

Além disso, houve uma grande variação no que se refere à discussão e negociação dos instrumentos com os atores ligados à política. Em todos os estados, os entrevistados não apontaram os deputados estaduais como fundamentais nesse processo, mas os sindicatos foram atores que, nos casos em que houve negociação, não se opuseram aos instrumentos. Já nos casos em que não houve negociação, a aceitação dos instrumentos ficou prejudicada.

É importante apontar que escolas, professores e diretores, ainda que representados pelos sindicatos, foram atores passivos nesse processo. Isto é, os entrevistados não mostraram uma preocupação das secretarias em como esses instrumentos seriam aceitos e utilizados por elas. Isso, como apresentado, pode ser uma das razões para a existência de práticas como o gaming nas escolas.

Esses fatores foram os principais que influenciaram as variações nas mudanças entre os estados e na sua implementação. Em Minas Gerais e em Pernambuco, houve uma contratualização de metas realizada entre secretaria e escolas, processo que não ocorreu no Espírito Santo e em São Paulo, nos quais as metas foram determinadas unilateralmente pela secretaria. No Espírito Santo, diferentemente dos demais, o nível socioeconômico dos alunos foi considerado na elaboração das metas, e houve uma preocupação de que não houvesse seleção de alunos no momento da realização da prova. Ainda, foi o único caso em que o planejamento estratégico estava de fato institucionalizado na secretaria.

Os governos estaduais pretendiam, com as reformas recentes, a melhoria do desempenho da educação dos seus respectivos estados. No entanto, esses instrumentos de avaliação e incentivo não são um fim em si mesmos. Devem, portanto, ser acompanhados de mudanças que fortaleçam e profissionalizem a burocracia, como tem sido feito por alguns dos estados analisados. Vale ressaltar que, mesmo nos estados em que tem havido esse fortalecimento da burocracia, as iniciativas ainda são insuficientes. Por exemplo, pouco tem sido modificado nas coordenadorias regionais existentes em quase todos os estados.

No que se refere à profissionalização da burocracia, foi muito citado pelos entrevistados o pouco conhecimento dos diretores, coordenadores pedagógicos e 
professores sobre a existência e o funcionamento das avaliações, índices, metas e a remuneração por desempenho. Isso também foi apontado por outras pesquisas. 0 Instituto Paulo Montenegro (2010a) mostrou que, em 2007, os sistemas de avaliação do rendimento escolar eram desconhecidos por $14 \%$ dos professores entrevistados nos grandes centros urbanos. Nesse mesmo ano, o Governo Federal lançou o Ideb. No entanto, o indicador permanecia desconhecido para $55 \%$ dos professores e a Prova Brasil foi lembrada espontaneamente por apenas $28 \%$ dos professores que lecionam no Ensino Fundamental. Em 2009, o Instituto Paulo Montenegro (2010b) observou que um terço dos gestores escolares desconhecia o Ideb das próprias escolas onde atuavam.

Foi mostrado, por meio da análise empírica, que mudanças constantes ocorreram no processo de reforma, ou seja, a efetividade das metas, indicadores e premiações foi influenciada por sua implementação, o que provocou ajustes e mudanças ao longo do tempo. Isso é evidente no caso do Espírito Santo, em que, baseado nos problemas apresentados pelos sistemas existentes em outros estados, formulouse um sistema que não apresentava os mesmos problemas e que não enfrentaria resistências dos atores ligados à política, como o sindicato.

\section{Considerações finais}

As metas e os indicadores de desempenho já se consolidaram na esfera federal há mais de duas décadas. Eles foram introduzidos no Governo Fernando Henrique Cardoso e fortalecidos durante o Governo de Lula, especialmente por meio do Plano de Metas Compromisso Todos Pela Educação e do PAR. Ainda que tenha havido experiências anteriores de avaliações em alguns estados, é no início dos anos 2000 que esses instrumentos foram disseminados de maneira mais intensa aos governos subnacionais, mais fortemente aos estados.

Além de acompanhar e cumprir as metas nacionais, os estados buscam cumprir suas próprias metas a fim de melhorar a qualidade da educação. Assim como em outros países da América Latina e do mundo, as metas e os indicadores educacionais entraram na agenda governamental brasileira.

Observa-se, portanto, que os estados possuíam objetivos comuns com a introdução da gestão por resultados nas políticas educacionais, que eram a melhoria da qualidade da Educação por meio de incentivos aos professores e diretores. Apesar disso, as mudanças nos quatro estados tiveram trajetórias distintas. A diferença entre elas é resultado das seguintes variáveis: da realização de reformas anteriores, da inspiração para a adoção da reforma, da situação administrativa das secretarias estaduais de educação e das redes estaduais de ensino, além do modo como as medidas foram implementadas e negociadas com a burocracia e os sindicatos. 
As reformas nos quatro estados têm três pilares comuns: currículo, avaliação e remuneração por desempenho. Os estados que não possuíam os dois primeiros, tiveram que implementá-los para a adoção da remuneração por desempenho, como foi o caso do Espírito Santo e de Pernambuco. Vale ressaltar que esses três pilares são a base das reformas que estão sendo implementadas, atualmente, em outros estados brasileiros.

No entanto, as reformas analisadas diferem nas mudanças em prol da profissionalização da burocracia e da accountability, que constituem a fragilidade das reformas estudadas. Em relação ao primeiro aspecto, a profissionalização da burocracia, observa-se que, em alguns casos, o processo de seleção do diretor escolar e sua formação foram modificados, especialmente nos casos em que ainda vigorava a indicação como processo de escolha. Além disso, foram promovidas mudanças na carreira dos professores e, mais recentemente, em São Paulo, nas coordenadorias regionais. Destaca-se, porém, que essas permanecem imunes às reformas na maior parte dos estados brasileiros.

No que se refere ao segundo aspecto, a accountability, ela ficou restrita à publicização dos resultados educacionais. A formulação da reforma não foi discutida amplamente com a sociedade civil - somente o foi, em alguns casos, com os sindicatos de professores -, sendo essa a principal fraqueza das reformas analisadas.

\section{Referências bibliográficas}

ABRUcio, F. L. . Os avanços e os dilemas do modelo pós-burocrático: a reforma da administração pública à luz da experiência internacional recente. In: BRESSER PEREIRA, L. C.; SPINK, P. (orgs.). Reforma do Estado e administração pública gerencial. 7. ed. Rio de Janeiro: FGV, 2006.

Reforma da gestão pública nos estados: avanços e desafios na institucionalização de uma agenda. In: CONSELHO NACIONAL DE SECRETÁRIOS DE ESTAdo e AdMInISTRAÇÃo (Consad). Avanços e perspectivas da gestão pública nos estados II. Brasília: Consad, 2010.

Abrucio, F. L.; GAETANI, F. Agenda, aprendizado e coalizão. In: ConselHo NACIONAL de SECRETÁrIOS dE ESTAdo E AdMINISTRAÇÃo (Consad); Fundação do DESENVOLVIMENTO AdMinistrativo (Fundap). Avanços e perspectivas da gestão públicas nos estados. Brasília: Consad; São Paulo: Fundap, 2006.

Abrucio, F. L.; LoUREIRO, M. R. Finanças públicas, democracia e accountability. In: BIDERMAN, C.; ARVATE, P. (Orgs.). Economia do setor público no Brasil. Rio de Janeiro: Elsevier, 2004.

ABrucio, F. L.; Pedrotı, P.; Pó, M. A. formação da burocracia brasileira: a trajetória e o significado das reformas administrativas. In: ABRUCIO, F. L.; LOUREIRO, M. R.; PACHECO, R. V. S. Burocracia e política no Brasil: desafios para o Estado democrático no século XXI. Rio de Janeiro: FGV, 2009. 
AlvareZ, L. Projeto melhora escolas da capital: tutoria a professores e a criação do cargo de 'coordenador de pais' geram resultados. O Estado de São Paulo, São Paulo, 22 maio 2010.

Centro latinoamericano de Administração para o Desenvolvimento (Clad). la responsabilización en la nueva gestion publica latinoamericana. Caracas: Clad; Buenos Aires: Eudeba, 2000.

ESPíRITO SANTO. Ensinando e aprendendo: oito anos da Nova Escola no Espírito Santo 2003 a 2010. Vitória: Sedu, 2010.

FARIA, C. A. P. DE; Filgueiras, C. A. C. As políticas dos sistemas de avaliação da Educação Básica do Chile e do Brasil. In: Hochman, G.; ArRetche, M.; Marques, E. (Orgs.). Políticas públicas no Brasil. 2. ed. Rio de Janeiro: Editora Fiocruz, 2007.

Formoso, A. JR. Burocratas de linha de frente e pressão por resultados na educação: experiências brasileiras em governos estaduais. São Paulo: FGV, 2009. 118 f. Dissertação (Mestrado) - Escola de Administração de Empresas de São Paulo, Fundação Getulio Vargas, São Paulo.

FREITAS, L. C. de. A avaliação e as reformas dos anos de 1990: novas formas de exclusão, velhas formas de subordinação. Educação \& Sociedade, v. 25, n. 86, p. 133-170, 2004.

GAETANI, F. As políticas de gestão pública nos governos estaduais: avanços assimétricos e impasses resistentes. In: ConselHo NACIONAL dE SECRETÁrIOS dE Estado e AdMinistração (Consad). Avanços e perspectivas da gestão pública nos estados II. Brasília: Consad, 2010.

Gall, N.; Guedes, P. M. A reforma educacional de Nova York: possibilidades para o Brasil. São Paulo: Fundação Itaú Social e Instituto Fernand Braudel de Economia Mundial, 2009.

GRAY, A.; JENKINS, B. From public administration to public management: reassessing a revolution? Public Administration, n. 73, p. 75-99, 1995.

GRUENING, G. Origin and theoretical basis of New Public Management. International Public Management Journal, n. 4, p. 1-25, 2001.

Hood, C. Public service management by numbers: why does it vary? Where has it come from? What are the gaps and the puzzles? Public Money \& Management, p. 95-102, april 2007.

InStituto PAulo Montenegro. Ser professor: uma pesquisa sobre o que pensa o docente das principais capitais brasileiras. In: FundAção VICTOR CIVITA. Estudos \& Pesquisas Educacionais. São Paulo: Fundação Victor Civita, 2010a. n. 1

Gestão escolar nas escolas pública de Ensino Básico das principais capitais brasileiras: o perfil do protagonista. Estudos \& Pesquisas Educacionais. São Paulo: Fundação Victor Civita, 2010b. n. 1

OSBoRne, D.; GAEBLER, T. Reinventando o governo. 6. ed. Brasília: MH Comunicação, 1995.

Peters, G. B. Os dois futuros do ato de governar: processos de descentralização e recentralização no ato de governar. Revista do Serviço Público, v. 59, n. 3, p. 298307, jul./set. 2008. 
PINTO, V. G.; SARAIVA, J. A. F. Gestão por resultados na educação: monitoramento e avaliação de projetos educacionais. In: GuImARÃES, T. B.; PordeUs, I. A.; CAMPOS, E. S. A. (Orgs.). Estado para resultados: avanços no monitoramento e avaliação da gestão pública em Minas Gerais. Belo Horizonte: Editora UFMG, 2010.

Programa de Promoción de la Reforma Educativa de América latina y el Caribe. Un llamado a la responsabilidad por los resultados. Rendición de cuentas en educación no 1. Forma e reformas de la educacíon, serie políticas, ano 5, no 15, jul., 2003.

PODguRSKY, M.; SPRINGER, M. Credentials versus performance: review of the Teacher Performance Pay Research. Peabody Journal of Education, v. 82, n. 4, p. 551-573, 2007.

Pollitt, C.; Bouckaert, G. Public Management Reform: a comparative analysis. UK: Oxford University Press, 2000.

Ribeiro, A. A. A agenda das metas e indicadores educacionais: disseminação, atores e desafios. São Paulo: FGV, 2010. 140 f. Dissertação (Mestrado) - Escola de Administração de Empresas de São Paulo, Fundação Getulio Vargas, São Paulo.

SECRETARIA dA EducAÇÃo do ESTAdo do Espírito SANTO. Apresentação. 2010.

SEGATTO, C. I. Como ideias se transformam em reformas: um estudo comparativo das mudanças educacionais orientadas pelo desempenho nos estados brasileiros. São Paulo: FGV, 2011. 134 f. Dissertação (Mestrado em Administração Pública e Governo) - Escola de Administração de Empresas de São Paulo, FGV, São Paulo.

SEGATto, C. I.; ABRUCIO, F. L. A disseminação das mudanças educacionais nos estados brasileiros: principais fatores explicativos. In: ENCONTRO DA ANPAD, 35., 2011, Rio de Janeiro. Anais... Rio de Janeiro: Anpad, 2011.

SISTEMA DE INFORMAÇÕES DA EdUCAÇÃo DE PERNAMBUCO. Índice de Desenvolvimento daEducação Básica de Pernambuco (Idepe). 2016. Disponívelem:<http://www.siepe. educacao.pe.gov.br/WebModuleSme/itemMenuPaginaConteudoUsuarioAction. do actionType=mostrar\&idPaginaltemMenuConteudo=5911>. Acesso em: 29 de abril de 2016.

WANG, L.; BECKETT, G. H.; BROWN, L. Controversies of standardized assessment in school accountability reform: a critical synthesis of multidisciplinary research evidence. Applied Measurement in Education, v. 19, n. 4, p. 305-328, 2006.

\section{Catarina Ianni Segatto}

Doutora em Administração Pública e Governo pela Fundação Getulio Vargas, pesquisadora na Johnson Shoyama Graduate School of Public Policy (University of Regina, Canada) e no Centro de Estudos em Administração Pública e Governo da Fundação Getulio Vargas, Brasil. Contato: catarina.segatto@gmail.com

Fernando Luiz Abrucio

Doutor em Ciência Política pela Universidade de São Paulo (USP), professor da Escola de Administração de Empresas de São Paulo/ Fundação Getulio Vargas e coordenador do curso de Graduação em Administração Pública na mesma escola. Contato: fabrucio@gmail.com 
RSP 